\title{
Educação e fascismo no Brasil: a formação escolar da infância e o Estado Novo (1937- 1945)
}

\author{
Ademir Valdir dos Santos \\ Universidade Federal de Santa Catarina, Brasil
}

\section{Resumo}

O Estado Novo foi o governo ditatorial liderado por Getúlio Vargas. Neste período a ação governamental foi caracterizada por buscar a formação de uma nacionalidade e identidade brasileiras. Neste estudo destacamos a orientação político-ideológica do Estado Novo que objetivou atingir as escolas elementares, especialmente nas áreas de imigração européia do sul do Brasil, gerando transformações pedagógicas. Analisamos edições de um jornal escolar intitulado Tudo pelo Brasil, elaboradas entre 1941 e 1944, e documentos da legislação educacional como relatórios de inspeção escolar e atas. Mostramos que os textos escritos pelas crianças da escola primária brasileira e transportados para o jornal escolar explicitam, através de sua forma e conteúdo, o ideário do regime político. Como atividade do currículo, o envolvimento infantil na elaboração do jornal poderia colaborar para a formação dos cidadãos de que necessitava o Brasil. No Estado Novo, a educação escolar se prestou à construção nacionalista idealizada pelo projeto fascista de Getúlio Vargas.

Palavras-chave

Educação; Nacionalismo; Fascismo; Infância; Brasil

\section{Introdução}

Na história do Brasil, Estado Novo é o nome do período de governo ditatorial que tinha como líder Getúlio Vargas. Situa-se entre 10 de novembro 
de 1937, quando foi proposta uma nova Constituição que estabelecia as bases do novo regime, e 29 de outubro de 1945, quando Vargas partiu para um exílio. Antes disso, o presidente já havia sido levado ao poder como representante provisório em 1930 e, mesmo após a fase da ditadura, foi reconduzido para um outro governo entre 1951 e 1954. Esta ditadura brasileira ocorreu num momento em que outras formações políticas autoritárias estavam ativas: "Mussolini chegou ao poder na Itália em 1923; Hitler, com sua ascensão à Chancelaria em 1933, acabou de desintegrar a República de Weimar; Salazar, em 1929, chegou a primeiro-ministro de Portugal; a Espanha se encontrava, entre 1936 e 1939, banhada no sangue de uma guerra civil" (Oliveira, Velloso, \& Gomes, 1982, p. 7).

Vários autores evidenciaram as relações entre o governo de Vargas e os regimes totalitários europeus, permitindo caracterizar o Estado Novo como uma expressão do fascismo (cf. Trento, 2005; Pandolfi, 1999; Paulo, 1994; Gertz, 1987). Neste ponto explicitamos ainda nossa concordância com Outhwaite e Bottomore, para quem "A definição de fascismo é inevitavelmente controvertida", ao mesmo tempo em que delimitamos a amplitude semântica atribuída ao termo:

Usado de maneira genérica, fascismo é uma palavra que designa um gênero singularmente multiforme de política moderna, inspirado pela convicção de que um processo de renascimento nacional (palingênese) se tornou essencial para pôr fim a um prolongado período de DECADÊNCIA social e cultural, e expressando-se ideologicamente em uma forma revolucionária de NACIONALISMO integral (ultranacionalismo) (Outhwaite \& Bottomore, 1996, p. 300).

A ação governamental no Estado Novo foi caracterizada por diretrizes para a formação de uma pretensa identidade brasileira, fator aglutinador em torno da idéia de configuração de uma nação única. Por todo o país, recursos variados foram utilizados na infiltração da ideologia pretendida, com ênfase naqueles que tinham um destino especial: o sistema educativo escolar. Ou seja: "Enfatizar a educação cívica e nacionalista era a principal orientação da política educacional. Objetivava-se formar indivíduos identificados com os 'interesses nacionais', integrados na tarefa de fazer do Brasil uma grande nação" (Bercito, 1990, p. 54).

O papel atribuído à educação escolar é o elemento fundamental que impulsiona nossas investigações sobre o estadonovismo: as escolas eram 
consideradas ambientes estratégicos para a formação do brasileiro, que viria a ser um homem também novo, um patriota devotado destinado a auxiliar na regeneração social da nação. Por isto, a formação das crianças e jovens recebeu um olhar especial do governo, num projeto com marcas ideológicas arraigadas.

Neste estudo pretendemos destacar mecanismos de orientação político-ideológica do Estado Novo que objetivaram atingir a rede de escolas elementares brasileiras, particularmente aquelas localizadas nas áreas de imigração européia do sul do Brasil, buscando implementar transformações pedagógicas e didáticas.

O objeto central da análise é o conjunto documental formado por onze edições de um jornal escolar intitulado Tudo pelo Brasil, do qual localizamos exemplares elaborados entre agosto de 1941 e fevereiro de 1944, produzidos na Escola Luiz Delfino, localizada em área de migração europeia. Os jornais eram elaborados mensalmente por alunos que frequentavam as segundas e terceiras séries da instrução elementar, com idade entre 9 e 11 anos de idade; podem ser considerados como um produto particular de literatura infantil, vinculado à atividade escolar. Consideramos, ao lado disto, a hipótese de que o conteúdo presente naqueles jornais infantis era o mesmo ministrado em sala de aula. E, para caracterizar o panorama construído no Estado Novo, bem como contextualizar as questões pedagógicas e didáticas estudadas quanto aos aspectos sociais, políticos e culturais, usamos também documentos da legislação educacional tais como relatórios de inspeção escolar e atas escolares. Dialogamos, ainda, com um referencial teórico que trata do papel atribuído à educação e à propaganda nos sistemas políticos fascistas.

\section{O Estado Novo de Getúlio Vargas: o fascismo brasileiro e suas estratégias de poder}

Durante a chamada 'era Vargas', notadamente no Estado Novo, as relações brasileiras com o ambiente político internacional variaram. De acordo com Faria e Barros (1986, pp. 53-61), o discurso de Vargas atacava o liberalismo e exaltava o social-fascismo, sendo que, entre 1934 e 1942, certo pragmatismo delineou uma política externa bipartida, definida, numa extremidade, por um pólo de forte comércio com a Alemanha e, noutra ponta, focada nas relações com os Estados Unidos. 
De fato, o novo regime contava com aliados e inimigos. Havia algum alinhamento entre a ditadura brasileira e inspirações fascistas de outras nações européias. Por exemplo, a Constituição de 1937, conhecida como 'Polaca', foi orientada em seus dispositivos trabalhistas pela Carta del Lavoro italiana. Outra questão interessante era a situação de um partido político: a Ação Integralista Brasileira. Como se afirma na obra Fascisti in Sud America, em que são tratados os mecanismos de criação de consenso com o fascismo de Mussolini entre os italianos emigrados para a América do Sul, especificamente para o Brasil, Argentina e Peru, configurou-se uma expressão fascista que distinguia a realidade brasileira daquela dos outros países: "(...) há, porém, no Brasil, da parte dos italianos da segunda geração e do ministro do exterior Ciano, uma incauta, senão breve, abertura de confiança em relação a um promissor partido 'irmão', a Ação Integralista Brasileira de Plínio Salgado" (Scarzanella, 2005, p. VIII) ${ }^{1}$.

Quanto ao 'integralismo', em 7 de outubro de 1932 seu líder, Plínio Salgado, lançou um manifesto criando a Ação Integralista Brasileira (AIB). Os partidários também buscaram visibilidade em 7 de outubro de 1934, quando 10.000 integralistas tentaram fazer uma manifestação na praça da Sé, em São Paulo, e entraram em choque com os comunistas; já em 12 de junho de 1937, cerca de 30.000 integralistas desfilaram pela avenida Rio Branco, no Rio de Janeiro. Mas, com a instalação do Estado Novo, um decreto extinguiu todos os partidos políticos, inclusive a Ação Integralista Brasileira. Como reação, os integralistas tentaram um assalto ao poder em 10 de maio de 1938, atacando o Palácio Guanabara, que abrigava Getúlio Vargas. Mas foram derrotados e presos (cf. Vargas, 1995, pp. 130-131).

Também os comunistas, cujo maior líder era Luís Carlos Prestes, faziam oposição. Em 1935 foi anunciada a criação da Aliança Nacional Libertadora (ANL), reunindo correntes antifascistas, tendo Prestes como presidente de honra. Mas logo a Aliança foi declarada ilegal e insurreições foram derrotadas, com o estabelecimento do estado de sítio em todo o país, aumentando o poder de Vargas. No ano seguinte a repressão ao comunismo foi intensificada, sendo feitas inúmeras prisões. Episódios desta época, envolvendo Prestes e sua mulher Olga, puseram em evidência as boas relações, naquele momento, entre Getúlio Vargas e a Alemanha de Hitler². 
O complexo quadro político e social da era Vargas e a implementação e difusão do integralismo no sul do Brasil são apresentados por Gertz (1987), que discute suas vinculações com os movimentos de preservação das culturas alemãs e italianas nas áreas coloniais de imigração. Trata, entre outros aspectos, do impacto conflituoso dos embates para a rede escolar das colônias de imigrantes. Na obra $O$ fascismo no sul do Brasil, especula sobre as possíveis relações entre 0 integralismo e conflitos de base étnico-racial naquela região, indicando que não somente aspectos do integralismo, mas também nacional-socialistas, ora se contrapunham, ora convergiam no plano das decisões individuais e coletivas locais e nas relações políticas com as esferas estaduais e federais.

Em 1937, foram feitas intervenções nos Estados que faziam oposição a Vargas e, apesar de previstas eleições para a Presidência da República, a divulgação de uma pretensa conspiração comunista forneceu os pretextos para que fossem aprovados o estado de guerra e a dissolução do Congresso e, em decorrência, que se implantassem o Estado Novo e sua Constituição.

Mas, apesar de uma situação anterior de relações externas amistosas, em agosto de 1942 foi decretado estado de guerra com a Alemanha e a Itália, após navios brasileiros terem sido afundados por submarinos alemães. Ou seja, o fato do Brasil entrar na guerra ao lado dos Estados Unidos e contra as forças do Eixo criou contradições internas na conjuntura política: a luta contra a opressão totalitária no plano externo contrastava com a manutenção interna da situação de anormalidade institucional que caracterizou a ditadura getulista.

As marcas fascistas do Estado Novo brasileiro foram reforçadas com a criação do Departamento de Imprensa e Propaganda (DIP), responsável pela censura aos meios de comunicação. Por esse motivo, esse período histórico é rico em publicações que enalteciam a imagem de Getúlio Vargas e os seus projetos de governo, dando contornos particulares ao fascismo brasileiro, em que a manipulação ideológica assumiu uma importância vital.

O uso da propaganda como artifício de poder é caracterizado por Paulo (1994), que situa a sua utilização desde a Primeira Grande Guerra e a associa à ascensão dos Estados fascistas que buscavam a obtenção de "consenso" das sociedades quanto às suas propostas, apostando na força e penetração ideológica da propaganda estatal: "A recuperação de uma glória 
passada perdida, a exaltação dos grandes heróis, a 'mística' do regime e da sua 'eternidade futura', a importância da 'raça', a juventude, a figura do Chefe, do Duce ou do Führer são agora os pontos-chave do trabalho de propaganda do Estado"; na mesma obra, a autora lembra que, ao lado do uso dos meios de comunicação, a implantação do fascismo é marcada "por uma acção mais centrada num dos mais 'clássicos' aparelhos de propaganda de Estado: o sistema de ensino" (Paulo, 1994, p. 15).

Considerado como expressão brasileira do fascismo enquanto gênero político, o Estado Novo também previu a utilização da educação escolar como aparelho ideológico: "O campo educacional foi um dos alvos eleitos. Era um espaço com poder de moldar a sociedade a partir da formação das mentes (...) e a educação seria a arena principal em que o combate ideológico se daria" (Schwartzman, Bomeny, \& Costa, 1984, p. 51).

Em 1938, num célebre discurso de Getúlio à nação brasileira, o líder falou de questões como as desigualdades de classe, o combate a ideologias extremistas e a dissolução dos chamados quistos raciais nas áreas de imigração. Destacamos um trecho em que se dirigiu à infância e juventude:

O Brasil tudo espera da juventude enquadrada perfeitamente nas aspirações do Estado Novo. Guardando as inspirações do passado e construindo a ordem e o progresso atual, é para a grandeza do futuro que volta as suas vistas. As novas gerações terão papel decisivo a desempenhar, pois o muito que já somos ainda é bem pouco diante do que poderemos ser, com as nossas imensas possibilidades. É necessário formar nessas crianças e nesses adolescentes a mentalidade capaz de levar o país aos seus destinos, mas conservando os traços fundamentais de nossa fisionomia histórica, com o espírito tradicional da nacionalidade, que o regime instituído é o único apto a cultuar na sua verdade. A essa necessidade correspondem os artigos da nova Constituição sobre a matéria educativa, orientando-a no sentido essencialmente cívico e nacionalista (Bercito, 1990, p. 41).

Segundo aquele ideário, era fundamental forjar as crianças e jovens. Assim, nas Comemorações do Estado Nacional - 1937 - 1942 - Na voz das classes e na palavra do chefe, editada em 1943, esta apologética publicação destinou um espaço às "Homenagens do Mundo Infantil", retratadas num texto que descreve a manifestação das crianças de escolas do Distrito Federal. A programação festiva foi realizada na praça Marechal Floriano, ocupada por milhares de crianças: 
No momento em que o Presidente desceu do carro em frente ao edifício do Palácio Municipal, toda a massa infantil, em coro orfeônico, entoou o Hino Nacional, seguindo-se-lhe outros hinos e canções patrióticas que arrancaram aplausos prolongados da multidão estacionada nas imediações.

Rematando as homenagens do mundo infantil carioca, como nota encantadora em todo esse programa de civismo, a menina Miriam Joppert de Moura, da escola Francisco Cabrita, saudou o Chefe do Estado Nacional. Sua excelência abraçou-a carinhosamente e disse ligeiras palavras de agradecimento e simpatia (Comemorações do Estado Nacional..., 1943, p. 45).

Delineados aspectos do contexto social e político que a ditadura de Vargas imprimia, vejamos, a seguir, como a população escolar foi atingida por diversas ações conjugadas à propagação ideológica dos objetivos do Estado Novo.

\section{Folheando o Tudo pelo Brasil}

Ao tomarmos o jornal escolar Tudo pelo Brasil como objeto, o que pretendemos é olhar de modo mais atento para a internalidade do trabalho educativo, na busca de fornecer novas compreensões sobre as práticas pedagógicas naquele momento histórico. Através da análise deste recurso didático, queremos destacar elementos para avaliação do quanto as correntes ideológicas do Estado Novo atingiram o cotidiano das escolas, se imiscuindo até mesmo em práticas pedagógicas das salas de aula. Igualmente, buscamos reforçar a tese de que as orientações normativas e de controle da ditadura atingiram desde os centros urbanos até localidades pequenas dos mais distantes pontos do extenso território brasileiro. Utilizaram-se mecanismos de produção e distribuição de material de propaganda que chegariam até as escolas, mesmo nas mais isoladas regiões rurais, mostrando a grande irradiação que marcou a penetração da campanha nacionalista durante o Estado Novo.

As crianças autoras do Tudo pelo Brasil estudavam na Escola Isolada Municipal Luiz Delfino, situada no atual município de Corupá, estado de Santa Catarina, no sul do Brasil, sob orientação da professora Juliana Kolas da Veiga Coutinho. É fundamental considerar duas circunstâncias históricas: primeiro, que embora esta instituição fosse então administrada pelo município, foi originada como 'escola alemã', mais uma representante das transformações históricas por que haviam passado as escolas estrangeiras 
que funcionaram no Sul do Brasil, nas regiões colonizadas por imigrantes europeus durante o século XIX e primeiras décadas do século $X X^{3}$; depois, que justamente no Estado Novo foi decretado 4 o fechamento das escolas estrangeiras no Brasil. Após 1938, essas instituições precisaram atender às mudanças administrativas e pedagógicas exigidas pelo Ministério da Educação e Saúde Pública, o que implicou sua transformação e integração aos sistemas escolares públicos; ou, em vários casos, significou a sua extinção por não conseguir atender a tais exigências legais.

Então, as escolas étnicas estrangeiras eram consideradas ameaçadoras da unidade e homogeneidade nacional pretendidas. Isto porque, contrariamente aos escopos nacionalistas fascistas, educavam crianças e jovens segundo critérios pedagógicos apoiados em valores e atitudes que nutriam devoção e sentimentos de pertencimento às nações européias de origem dos imigrantes, afrontando a formação da brasilidade. Diversas obras da época faziam vigorosa defesa dos propósitos do Estado Novo, reafirmando suas intenções: "Nenhum governo no Brasil enfrentou o problema da nacionalização, com a decisiva energia do Govêrno atual. A própria feição do regime, criando as responsabilidades diretas, facilita a ação e o contrôle das medidas repressivas e das educadoras" (Bethlem, 1939, p. 14).

Dentro deste contexto, entendemos que fatos particulares observados numa escola são expressões de características gerais presentes, também, em outras unidades escolares, naquelas circunstâncias históricas ${ }^{5}$. Distantes do cenário planejado das comemorações que celebravam a figura de Vargas na então capital do Brasil (a cidade do Rio de Janeiro), as crianças sulinas utilizavam seu pequeno jornal escolar como veículo das expressões cívicas preconizadas pelo ideário nacionalista. Nas diversas edições pesquisadas podemos encontrar descrições de comemorações e homenagens que eram realizadas, compondo um currículo intensivo de exaltação a Getúlio Vargas e ao Estado Novo. No exemplar de número 4, datado de novembro de 1941, encontramos a matéria intitulada "Inauguração dos Retratos dos dois Grandes estadistas Dr. Getúlio Vargas e Dr. Nereu Ramos", onde podemos perceber o tom de veneração que as descrições de comemorações na capital federal procuravam evocar, mesmo que ali reduzido ao espaço de uma pequena comunidade escolar rural: 
No dia 10 de novembro deu-se na nossa Escola a festa civica da Inauguração dos retratos do Dr Getúlio Vargas e Nereu Ramos. Assistiram a solenidade os alunos e a professora alguns Paes. Juliana K. V. Coutinho fez uma oração sobre a data de 10 de novembro que todos ouviram com grande atenção. Em seguida cantemos "Hino Nacional". E assim terminou um belo programa organisado por nossa professora, os alunos recitaram e foi-nos distribuídos doces e balas.

Criança - Orgulha-te do Brasil ter um presidente como o Dr. Getúlio Vargas (sic) (Escola Isolada Municipal Luiz Delfino, 1941).

Os textos dos jornais eram manuscritos e ilustrados sobre folhas de papel com linhas. Portanto, os exemplares têm um aspecto artesanal, um diferindo do outro quanto à composição estética, embora guardando um conteúdo idêntico. Um mesmo número do Tudo pelo Brasil, por ter sido copiado pelas mãos de diferentes crianças, apresentava contrastes quanto ao tipo de escrita e sua disposição nas páginas, bem como diferiam os desenhos, uma vez que podiam ter sido feitos (ou copiados) por autores diversos.

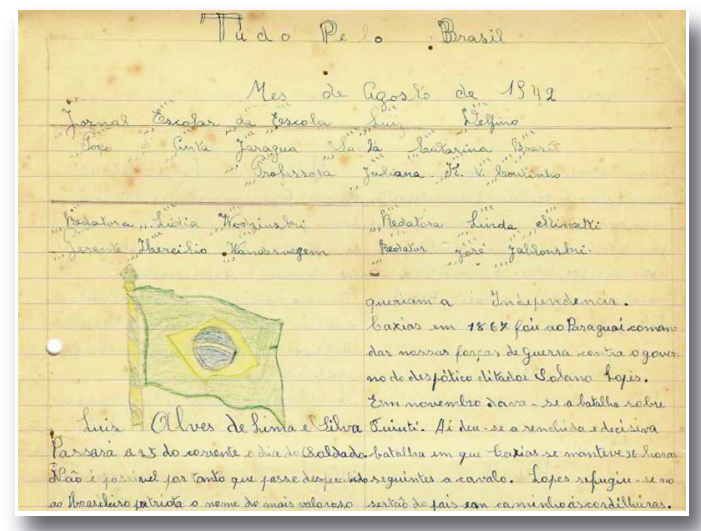

Figura 1 - Aspecto do jornal escolar Tudo pelo Brasil

Fonte: Arquivo Histórico Municipal Eugênio Victor Schmöckel - Santa Catarina - [1942]

O jornal tinha um redator, um gerente e dois repórteres. Contudo, percebe-se a influência da professora, apresentada em algumas redações como "estimada", como alguém que sempre demonstrava "esforço, carinho e dedicação (...) para elevar sempre o nome da nossa escola" (Escola Isolada Municipal Luiz Delfino, 1941). Sabemos que atuava na escola desde junho de 1929. Era uma senhora católica, com salários pagos pela prefeitura de Jaraguá 
do Sul, a qual administrava o então distrito de Hansa Humboldt, hoje município de Corupá. Sua habilitação era provisória, pois não possuía diploma de normalista 6 . A professora Juliana atendia as três séries num mesmo turno, em uma única sala de aula, caracterizando uma escola multisseriada. As atividades de Educação Física e Ensino Religioso ficavam a seu encargo, bem como o restante do currículo que constava de Linguagem, Aritmética, Geografia, História e Noções Comuns. Envolver as crianças na produção do jornal escolar significava atender aos compromissos de formação cívica infantil que foram exigidos dos professores durante o Estado Novo e que, nesse caso, encontravam viva resposta na atuação da professora.

Um espírito de exaltação patriótica marcou o Tudo pelo Brasil. Uma variedade de conteúdos curriculares da escola elementar foi transposta para o jornal escolar. Nesse sentido, podemos notar que havia influência docente sobre a seleção do que poderia, ou não, ser incluído a cada edição. Evidencia-se, com isso, o papel dos professores como cumpridores das prescrições curriculares previstas na legislação educacional, impregnadas do teor moralizador e de perceptíveis marcas ideológicas do fascismo de Vargas. Cabia aos alunos copiar os textos previamente selecionados, ilustrar as páginas do jornal com seus desenhos a grafite e coloridos com lápis-de-cor. Embora predominem conteúdos revisados pela professora, há algumas inserções de textos que julgamos ser de exclusiva autoria das crianças, em função de sua redação mais espontânea, exprimindo um potencial discursivo próprio de estágios iniciais de domínio da escrita, inclusive com a presença de erros ortográficos e gramaticais.

Tanto os textos do jornal quanto suas ilustrações caracterizam os ditames de formação da nacionalidade. Percebemos, por exemplo, a ênfase nos conteúdos da História do Brasil, trazidos sob uma visão que enaltece os heróis e benfeitores da pátria, homens e mulheres cujos feitos deveriam ser imitados, orientando a conformação das crianças e jovens aos modelos apresentados. De fato, com a reforma no campo educacional exigida pelo Estado Novo, foram introduzidas modificações no currículo das escolas brasileiras, com destaque para algumas matérias que poderiam contribuir incisivamente na formação cívico-moral infantil e juvenil, incorporando até mesmo elementos de militarização: 
$\mathrm{Na}$ base do sistema educativo do Estado Nacional, como substrato de seu conteúdo, como seu tríplice e invariável fundamento, a educação física, os trabalhos manuais e o ensino cívico. A educação física desperta a atividade e conduz ao senso da disciplina e do dever e, mais tarde, ao adestramento esportivo e militar; os trabalhos manuais estimulam o gosto das profissões, combatem os hábitos do intelectualismo ocioso e parasitário e formam a consciência social inerente à ordem corporativa; e o ensino cívico reage contra a indiferença dos princípios morais e contra as tendências desagregadoras, inspira a noção da continuidade da nossa História e dos valores eternos de nossa Raça e o temos visto exteriorizado nos desfiles comovedores da Juventude Brasileira (Bercito, 1990, p. 57).

Vargas era sempre destacado. Assim, mesmo em sua singeleza, aquele jornal infantil atendia aos preceitos da propaganda fascista para os quais é imprescindível louvar o grande Chefe. No tratamento dado pelas crianças ao ditador buscava-se caracterizar uma relação filial, 'de pai para filho', conferindo-Ihe a alcunha de 'grande pai da nação'. Este tom apologético era essencial quando se tratava de mencionar Getúlio Vargas, sendo que transpassava necessariamente todos os textos produzidos naquele contexto, desde aqueles aprovados pela imprensa e divulgados nas mídias oficiais de grande abrangência (como o rádio, por exemplo) até os ingênuos jornais escolares. Esta forma de tratamento é descrita por Alzira Vargas, que não somente era filha do presidente, mas que atuou junto ao gabinete de governo. Na obra Getúlio Vargas, meu pai, ela mesma se vê confusa quanto às formas com as quais poderia se referir à figura paterna:

Em conseqüência das novas funções, eu precisava fabricar também um título para meu Pai. Não podia me aproximar de um Ministro de Estado e dizer: «O Papai o recebe agora». Referir-me a êle como "O Sr. Presidente» parecia-me, além de pedante, ridículo. Alguns de meus colegas, a distância, chamavam-no, conforme a moda do dia: "O Chefe», «ll Capo», "O Boss», «S. Excia.», «El Jefe». O mais comum era "O Chefe». Nenhum desses apelidos me agradava particularmente aos ouvidos. Depois de vários engasgos, um dia, a frase brotou natural: "O meu Patrão pede que Ihe transmita o seguinte recado». Pronto, tinha encontrado a solução (Amaral Peixoto, 1960, pp. 243-244).

O primeiro exemplar analisado do Tudo pelo Brasil, datado de agosto de 1941, trazia dois diferentes textos sobre Caxias $^{7}$, um sobre Tiradentes ${ }^{8} \mathrm{e}$ outro sobre a Independência ${ }^{9}$. A edição seguinte, de setembro, louvava a Pátria e outras personagens históricas como José Bonifácio ${ }^{10}$ (Escola Isolada Municipal Luiz Delfino, 1941). 
O jornal de outubro fala do Descobrimento da América, de Deodoro ${ }^{11}$ e de Santos Dumont ${ }^{12}$. Merece atenção um relato dos alunos sobre a sua própria participação nas solenidades de inauguração da Prefeitura de Jaraguá do Sul, considerada uma oportunidade ímpar principalmente porque o intendente Nereu Ramos, especialmente designado por Getúlio Vargas, esteve presente:

Nós fomos a inauguração da nova Prefeitura Municipal de Jaraguá, viagemos com o trem especial, no qual tomamos logar no quinto vagão, no qual tomarão o logar os estudantes do Ciminário de Hansa, partimos as doze horas.

Estavam todos muito alegres catando e dando vivas ao Dr. Getúlio Vargas Dr. Nereu Ramos. Tte. Leônidas C. Herbster D. Darci Vargas D. Beatriz Ramos e demais autoridades do nosso município. Chegamos em Jaraguá desfilemos em dirição a nova Prefeitura aonde estavam muitos alunos do Grupo de Jaraguá e Hansa, os Colegios das caríssimas irmãs da divinada Providencia e muitos alunos das escolas municipais e estaduais. Também esta a 1a. comp. Do 130. B.I. de Joinville com o seu digníssimo comandantes.

As três horas estavam todos desfilados em frente a nova prefeitura e as 4 horas chegou a V.E. com toda acumitiva o qual foi saudado pela 1a. companhia do 13 B.I e toda a juventude escolar entre vivas e palmas, e a agitação das bandeiras, estávamos sempre atentos as ordens de nossa professora as quais eram sempre dadas pelo nosso dignisimo inspetor Sr. João Romario Moreira, o qual com grande abilidade orientava o desfile escolar (sic) (Escola Isolada Municipal Luiz Delfino, 1941).

A presença desse texto, apresentando dados da história de uma pequena cidade do interior, confere um caráter especial ao jornal escolar. Através da linguagem daqueles estudantes, preserva e nos traz o sabor do fato, revelando aquele específico contexto social. Ingenuamente, o ideário nacionalista é explicitado. Mostra também a força dos representantes de Getúlio Vargas e da imagem do grande Chefe que se pretendia incutir, nutrindo no imaginário infantil a imagem de um líder único. O populismo getulista foi construído com extrema astúcia.

O fato relatado pelas crianças reproduz, em pequena escala e no cenário de uma localidade interiorana, aquelas grandes paradas e desfiles promovidos na capital federal. A descrição feita efetivamente documenta um fato histórico importante para aquela região e os minuciosos detalhes fornecidos pelo texto infantil são confirmados por outros registros históricos ${ }^{13}$. Como reafirma Bercito (1990, pp. 48-49), "(...) durante o Estado Novo foram promovidos pelo DIP eventos públicos destinados a difundir as realizações do 
governo e criar um clima de comunhão coletiva: inaugurações, visitas a indústrias e obras caritativas, grandes eventos de massa comemorativos das datas nacionais".

O exemplar de novembro de 1941 traz textos sobre a bandeira nacional, a data de 10 de novembro de 1937, a atuação de Vargas e do Interventor Nereu Ramos, este o designado pelo ditador para administrar o Estado de Santa Catarina desde a implantação do novo regime. Nutria-se a conveniente imagem do governo: os atos oficiais e seus protagonistas continuavam sendo exaltados.

Era abril de 1942. O jornal escolar não podia deixar de falar sobre a data de 19 de abril: o aniversário de Vargas! O presidente era figura a ser festejada em toda parte e o relato da comemoração escolar consta no Tudo pelo Brasil, sendo assinado por uma aluna do $3^{\circ}$ ano chamada Emilia Moretti:

O aniversário do Presidente Vargas nesta escola. Aos desenove dias do mês de abril de mil novecentos e quarenta e dois (1942) associando-se aos festejos do natalicio do Presidente Vargas, foi organisado uma festa interna nesta escola, regida pela professora regente, Julian K.V. Coutinho.

Tendo comparecido os alunos matriculados nesta escola, cantaram aclamaram recitaram saudações e cantaram hinos (sic) (Escola Isolada Municipal Luiz Delfino, 1942).

Na propaganda do Estado Novo, Getúlio era representado por uma imagem paternal. Diversas ilustrações e fotografias da época mostram-no dirigindo-se à juventude. Na mesma direção, a constante vinculação de sua imagem à legislação trabalhista e às reformas sociais que empreendera o apresentavam como "pai dos trabalhadores" e "pai dos pobres". Foi elevado à condição de mito:

A construção da nação tinha em Getúlio Vargas seu grande guia. Sua imagem foi bastante cultivada pela máquina de propaganda do regime. Nas publicações oficiais, nas biografias, nos eventos de massa, nas fotografias afixadas em todos os lugares, enaltecia-se a figura do presidente. Reforçava-se seu poder carismático ora apresentando-o como um homem do povo, ora dotando-o de qualidades excepcionais. Construía-se a imagem do líder identificado com os interesses nacionais, capaz de empreender as reformas necessárias ao país (Bercito, 1990, p. 44).

Noutro texto a brasilidade é exaltada, ao mesmo tempo em que há recorrências aos argumentos étnico-raciais típicos do fascismo, aludindo à presença de estrangeiros. Isto porque uma das problemáticas que mais 
incomodava o Estado Novo era a imigração européia, que havia sido incentivada desde o Império e nas primeiras décadas da República, mas então configurava conflitos sociais e culturais. Sob a ótica governista, as gerações descendentes de imigrantes cultivavam muito mais os costumes e hábitos trazidos dos países de origem. Por isso, era preciso despertar em todas as comunidades com elevado percentual de estrangeiros os sentimentos de pertencimento ao Brasil, o que resultaria, consequentemente, no abandono das referências culturais alienígenas. Voltamos aos jornais escolares, onde encontramos:

Sou brasileiro. Tenho orgulho de dizer que nasci neste grande país, que é o meu Brasil. Todos os que nascem no Brasil, mesmo que sejam filhos de estrangeiros são brasileiros. Nós todos devemos amar a nossa pátria, a terra onde nascemos. Quem não ama sua pátria é um monstro. O Brasil é um país imenso e cheio de riquezas. É quase tão grande como a Europa (Escola Isolada Municipal Luiz Delfino, 1942, grifo nosso).

As expressões usadas são fortes, suscitando nos jovens alunos sentimentos primários de um patriotismo forjado. Ao mesmo tempo, contribuem na criação de um clima de hostilidade para com outras formas de pensar. $\mathrm{O}$ objetivo deste tipo de mensagem era atingir as crianças e jovens filhos de imigrantes, especialmente naquelas colônias do Sul do Brasil, onde a campanha de nacionalização através da educação visava transformar as escolas em celeiros de formação de futuros cidadãos devotados exclusivamente à Pátria brasileira.

Um exemplo da xenofobia fascista do Estado Novo nos é dado por Bethlem (1939, p. 15) quando descreve a intervenção da campanha nacionalista na Escola Alemã de Curitiba. Nesta instituição, segundo relata aquele autor, o ensino era ministrado em alemão e o currículo centrado nos mesmos conteúdos das escolas situadas na Alemanha. Conforme suas palavras: "Perdia-se a sensação de Brasil dentro da Escola". Também é relatada a rigorosa ação dos oficiais do exército brasileiro naquela instituição, movida por um fundamento étnico discriminatório. Para defensores da ideologia fascista como Bethlem, para que os intentos da nacionalização fossem atingidos era vital mais do que intervir nas escolas; era preciso agir sobre outras instituições sociais: "Era vencendo seus grandes baluartes - lar, igreja e escola - que nós, brasileiros, com todas as forças, conseguiremos manter a harmonia nacional, fazendo com que os nossos patrícios, filhos de 
todas as origens, só falassem a nossa língua, só amassem nossa Pátria, só servissem ao Brasil" (Bethlem, 1939, pp. 18-19).

Em alguns de seus aspectos, a intervenção da campanha nacionalista estava relacionada a um fundamento racial. No livreto $O$ Brasil é bom, uma cartilha com 30 pequenos textos destinada à infância e aos seus familiares, cuja pretensão era "esclarecer" sobre o Brasil sob o regime do Estado Novo, encontramos amostras de propaganda nacionalista parametrizada pela questão da raça:

O Brasil é bom porque não faz distinções de raças. Porque não tem preconceitos de cor, nem de religião.

(...) Filho de japonês, - nasceu no Brasil, é brasileiro. Filho de alemão, - nasceu no Brasil, é brasileiro. Filho de turco, - nasceu no Brasil, é brasileiro. Filho de italiano, - nasceu no Brasil, é brasileiro. Todos são brasileiros, com os mesmos deveres e direitos. Todos devem respeitar a Pátria dos seus pais, mas devem querer e amar, acima de tudo, o Brasil (Departamento Nacional de Propaganda, 1938).

Podemos relacionar este texto às preocupações governistas com as colônias de imigrantes estrangeiros no Sul. Nesse ambiente, o conjunto de atitudes xenofóbicas que vinha sendo nutrido desde o período da Primeira Guerra Mundial se mostrou de várias formas. Durante os anos da Segunda Guerra Mundial, a 'perseguição' aos imigrantes europeus alemães e italianos, entre outros grupos, assumiu caráter mais contundente. Os relatos do que foi vivido pelos diversos grupos étnicos são apresentados por vários estudiosos ${ }^{14}$. Autores como Gertz (1987) e Scarzanella (2005) confirmam que a região meridional brasileira abrigava uma variedade de manifestações sociais entendidas como expressões do nazismo e do fascismo, ou então das formas políticas particulares que assumiram no território brasileiro o comunismo, além do chamado integralismo. Tomando esses fatos como justificativa para sentir-se ameaçado e reagir, o Estado Novo entendia justificáveis até mesmo suas intervenções com maior violência. Como reafirmam Outhwaite e Bottomore (1996, pp. 300-301), é possível localizar um "minimum fascista" entre as controvertidas definições de fascismo, mas há um acordo quanto a sua "violência imperialista e racista" e a incorporação, entre outros elementos, do "racismo biológico".

No âmbito da educação, por exemplo, notamos que os serviços de inspeção escolar, responsáveis pela fiscalização e controle das atividades 
escolares, verificavam a origem racial das crianças. É o que evidencia um termo de visita de inspeção realizada na Escola Isolada Municipal Luiz Delfino em 30 de outubro de 1941, onde se registraram as seguintes observações sobre as crianças: "Alunos: pouco desembaraçados mas bem disciplinados; há 10 crianças caboclas, 14 de origem italiana, 13 de origem polonesa e 3 de origem alemã e suíça" (Escola Isolada Municipal Luiz Delfino, 1941). O documento consultado ratifica a utilização da inspeção escolar pela campanha nacionalista como forma de controle (cf. Santos, 2008). A questão racial estava presente. Dentre os elementos da constituição da nacionalidade, preconizava-se "(...) o da erradicação das minorias étnicas, lingüísticas e culturais que se haviam constituído no Brasil nas últimas décadas, cuja assimilação se transformaria em uma questão de segurança nacional" (Schwartzman et al., 1984, p. 142).

Irônica e paradoxalmente, o mesmo discurso de exaltação da superioridade racial que se pretendia combater foi assimilado e lançado como arma de defesa ideológica nos limites do fascismo brasileiro. Por exemplo, na época em que os jornais escolares foram produzidos, Getúlio Vargas já havia tornado público seu rompimento com as nações do Eixo. Então, na literatura escolar agora cabia contrapor os heróis brasileiros às figuras de Hitler e Mussolini. Se outrora a atuação do exército brasileiro e de outros grupos governistas fora, em maior ou menor grau, inspirada em moldes do nazifascismo, após 1941 o 'novo' objetivo era combater a disseminação, em território brasileiro, da simpatia por aqueles mesmos líderes europeus que antes serviram de modelo para o autoritarismo de Getúlio e de seus comandados.

As controvertidas mudanças que acompanharam a era Vargas nas relações políticas internacionais e tiveram impactos nas decisões internas do fascismo brasileiro assumem tonalidades curiosas quando lemos um relato feito pela filha do "Chefe". Alzira Vargas lembra uma viagem feita à Europa em 1937 e faz considerações a respeito do instável cenário político internacional. Especialmente sobre sua visita à Alemanha, contou ao pai o que observou da educação juvenil sob o nazismo:

Não tenho a menor dúvida de que êste país se prepara a guerra e guerra próxima. Dois gigantescos oficiais da Guarda Negra, às ordens de mamãe, nos acompanharam dia e noite e nos fazem visitar as obras do Führer. Fomos ao Ginásio de Hitler: os exercícios físicos a que se submetem meninos de 13 e 14 anos visam exclusivamente a adestrá-los para combater. Rastejam no chão 
como se estivessem se movendo em um campo de batalha, sob metralhadoras. Atravessam estreitos e longuíssimos tubos de ferro como para habituar os olhos à escuridão, os pulmões à precariedade de ar puro e o corpo à exigüidade de uma trincheira. Lançam pedras, pedaços de madeira e objetos pesados a grandes distâncias, como quem lança uma bomba. Escalam muralhas de 2 a 3 metros com a rapidez e o silencio de quem assalta uma posição fortificada (Amaral Peixoto, s.d., p. 283).

Igualmente o projeto do Estado Novo reservara um lugar especial à infância e juventude. Observe-se a fotografia feita em uma região do sul do Brasil naquela época e as eventuais semelhanças com o relato sobre a formação de crianças e jovens na Alemanha nazista que foi feita pela filha de Getúlio Vargas a seu pai.

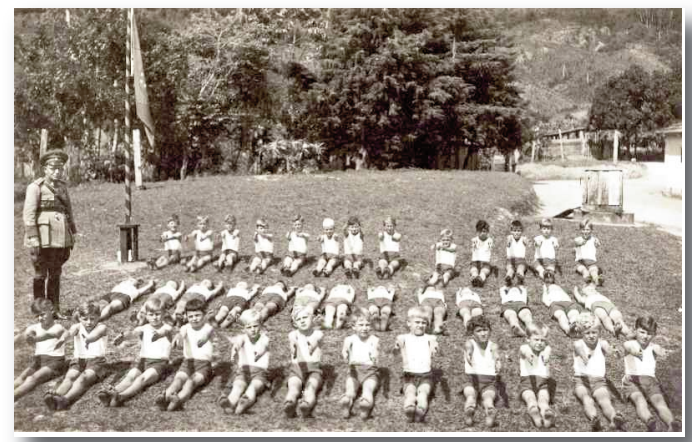

Figura 2 - Aspectos da educação física na escola no sul do Brasil, com caráter militarista, durante a campanha nacionalista do Estado Novo

Fonte: Arquivo Histórico Municipal Eugenio Victor Schmöckel - Santa Catarina - [194-?]

Na edição de agosto de 1941, o jornal escolar reproduzia trechos do já citado livreto $O$ Brasil é bom, em que podemos distinguir as mensagens subliminares, as sutilezas ideológicas, tudo isso com intenção de caracterizar a nacionalidade considerada legítima: "Não são brasileiros os que assim não procedem. E o Brasil não quer no seu solo maos brasileiros. O Brasil acolhe gente de todas as raças e de todos os continentes" (sic) (Escola Isolada Municipal Luiz Delfino, 1941).

O jornal escolar Tudo pelo Brasil pode ser entendido como mais uma entre tantas ferramentas de propaganda ideológica do projeto fascista de 
Getúlio Vargas destinada às crianças brasileiras. É importante destacar que o Ministro da Educação, Gustavo Capanema, além de propor uma reforma educacional em sintonia com a idéia de construção da nação, foi autor da proposta de Organização da Juventude Brasileira. Sobre tal questão Alzira Vargas comenta: "Era mais ou menos adaptada para o clima brasileiro, uma cópia da organização fascista dos jovens 'Balillas'. O hino da juventude, a bandeira da juventude foram criados, divulgados e usados; o resto ficou tudo no papel" (Amaral Peixoto, s.d., p. 350).

Nos jornais escolares dos meses de maio, agosto e outubro de 1942 apareciam, novamente, diversas referências a fatos e personagens da história brasileira. O exemplar de novembro de 1943 comenta a Proclamação da República e o dia da bandeira. O último jornal que encontramos data de fevereiro de 1944. Ali aparecem matérias sobre o Exército Nacional e Olavo Bilac ${ }^{15}$. "Sou Brasileira!" é o título de uma matéria que destacamos:

Tenho orgulho em dizer que sou Brasileira, porque aqui nesta bela nação vivem todos, ricos e pobres, brfasileiros e estrangeiros, brancos e pretos, com os mesmos direitos, com a mesma liberdade!

Vivemos todos debaixo da mesma bandeira - a gloriosa Bandeira Nacional.

A professora ensinou-nos que no Brasil há de tudo. É um país é um país rico.

Mas, para que sejamos dignos de sua grandeza, devemos trabalhar, respeitar as leis, acatar as ordens das autoridades, porque sem ordem não pode haver progresso, conforme a divisa da nossa Bandeira.

Quando lanço um olhar para o meu Brasil e lembro-me de tudo isso, não sinto finveja de nenhum outro País, pelo contrário ergo a cabeça e digo com orgulho SOU BRASILEIRO (Escola Isolada Municipal Luiz Delfino, 1944).

Em nossa busca por documentos produzidos nas escolas primárias durante a era Vargas encontramos, ainda, nos registros da mesma escola, várias atas de comemorações cívicas. Esses papéis, todos redigidos pela professora, comprovam a grande quantidade de solenidades que aconteciam na escola. Eram momentos que objetivavam a educação moral e cívica. Fazemos referência a tais atas porque relatam, a nosso ver, atividades que aconteciam no dia a dia escolar e que possuíam o mesmo objetivo ideológico dos jornais escolares. Por exemplo, de uma ata datada do dia 19 de novembro de 1941 transcrevemos o programa de homenagem à bandeira brasileira:

O Programa

1 - Hasteamento da Bandeira

2 - com o Hino Nacional Brasileiro 
3 - Saudação a Bandeira pela aluna: Miranda Zanella

4 - A Pátria pela aluna: Adélia Moreti

5-O Brasil : Paulo Moretti

6-A Terra Brasileira : Ceverino Zapella

7 - Hino a Bandeira pelos alunos

8 - Terra boa dois

9 - Hino do Estado S. Catarina

10 - Marcha pelos alunos

11 - Hino Getúlio Vargas

(Escola Isolada Municipal Luiz Delfino, 1941).

O teor do programa destaca vários pontos basilares do patriotismo que se pretendia forjar, enfatizando aspectos do Brasil e, inexoravelmente, enaltecendo a Getúlio Vargas. A relação das atividades programadas para a cerimônia que teve lugar na escola traz os traços da propaganda fascista e a intenção de veicular as idéias do governo ditatorial. O item 10, por sua vez, ao referir-se a uma "Marcha pelos alunos", destaca o caráter militarista que foi imposto a algumas rotinas escolares: orientadas pelos seus professores, as crianças deviam formar fileiras e pelotões para depois desfilar pelos arredores da escola, a moda militar. Pois do mesmo modo que nos grandes eventos públicos destinados a festejar Vargas e o Estado Novo, as homenagens cívicas que precisavam ser realizadas nas escolas brasileiras tinham o objetivo de popularizar o regime e criar simpatizantes. Sabemos que espalhafatosos eventos públicos foram promovidos com periodicidade durante o Estado Novo: "Essas comemorações faziam-se geralmente em grandes estádios (Vasco da Gama, Pacaembu) ou avenidas. Constavam de desfiles de escolares, operários, militares, demonstrações de educação física, canto orfeônico, bandas" (Bercito, 1990, p. 48). Dentro das unidades escolares se buscou reproduzir, em pequena escala, a grandiosidade daquelas marchas.

\section{Outros indicativos}

Selecionados e transportados para um veículo com produção e fim especiais - o jornal escolar -, os textos grafados pelas crianças de uma escola primária brasileira, em sua forma e conteúdo, explicitam o ideário do regime político então presente. Enquanto atividade do currículo escolar, o envolvimento dos estudantes na elaboração do jornal poderia colaborar para a formação dos cidadãos de que necessitava o Brasil. Assim, no momento do 
Estado Novo, a educação escolar se prestava, oficialmente, aos ideais da construção nacionalista.

Nesse caso, consideramos a função ideológica da educação, que contribuía para a moldagem da mentalidade popular e a formação de valores nacionalizantes. Os jornais escolares, em suas imagens e textos, demonstram a realização do caráter doutrinário exigido dos professores junto às crianças. Nas páginas do Tudo pelo Brasil, artesanalmente construídas, as ilustrações tonalizadas em lápis de cor que até hoje conserva a vivacidade mostram o quanto também a imagem pretendia auxiliar na formação de opinião. Mapas do Brasil, bandeiras, heróis nacionais, cenas possivelmente coladas de algum livro didático, além do próprio título Tudo pelo Brasil em verde-amarelo, assim demonstram e buscam reforçar os objetivos de formação cívica dos estudantes. Filhos de uma mesma matriz ideológica, transcritos manualmente de exemplar para exemplar, textos e imagens faziam a apologia do fascismo brasileiro de Getúlio Vargas e de seus representantes.

Segundo o ideário do Estado Novo brasileiro, nas escolas era preciso exaltar o patriotismo e evidenciar os apelos nacionalistas. O jornal Tudo pelo Brasil, de fato, constituía-se em mais um elemento do conjunto de práticas doutrinárias que se davam na escola. Nesse caso, agindo diretamente na formação discente. Como artifício pedagógico, buscava superar o ensino: a formação do caráter era seu escopo. O jornal pode ser entendido como um elemento da realização do ideário do governo brasileiro, no seio da escola, espelhando os interesses do sistema político.

Algumas escolas públicas, que eram remanescentes históricas de antigas escolas alemãs, foram tidas como locais de combate a uma pretensa obra de germanização que ameaçava a política de nacionalização do Estado Novo. A instauração da ordem, em oposição a qualquer movimento desnacionalizador, deveria ser evidenciada: "A ordem transformou-se em conceito-chave para o novo regime brasileiro" (Almeida, 1998, p. 142). À educação cabia forjar mentalidades. Esses jornais escolares atuaram como veículo doutrinador. A formação das crianças e jovens identificados com a ideologia do governo era necessária.

Cremos que esta reificação da instrumentalidade oferecida pelo ensino formal, percebido e idealizado como veículo reprodutor ideológico e formador de gerações fiéis aos paradigmas políticos eleitos pelo Estado emerge de forma 
contundente a partir da exacerbação do ideário político nacionalistas das décadas de 30 e 40 (Almeida, 1998, p. 156).

As representações do Brasil e de Getúlio Vargas 'ensinadas' através do jornal escolar se constituíam numa visão de personagens e fenômenos históricos a serviço de uma idéia de formação de nacionalidade: "A constituição da nacionalidade deveria ser a culminação de toda a ação pedagógica do ministério, em seu sentido mais amplo. (...) Primeiro, haveria que dar um conteúdo nacional à educação transmitida nas escolas e por outros instrumentos formativos" (Schwartzman et al., 1984, p. 141). E como demonstra o teor do relatório Ensino Primário Geral - 1944 - Informação anual à-cêrca da organização e aproveitamento, documento emanado do Departamento Estadual de Estatística do Estado de Santa Catarina que devia ser preenchido por todas as unidades escolares, no item IV deviam ser informadas todas as "Instituições Intra-escolares" tais como o Clube de Leitura, o Clube Agrícola, o Pelotão de Saúde e outras mais, que indicavam o atendimento de políticas de nacionalização em andamento, tais como o Escotismo, a Liga Pró-Lingua Nacional, o Orfeão Escolar e os Jornais Escolares (Instituto Brasileiro de Estatística/Departamento Estadual de Estatística do Estado de Santa Catarina, 1944).

Os valores que interessavam ao governo brasileiro foram impostos. A escola, naquele momento submissa a esse ideário, alimentava em suas tarefas pedagógicas os símbolos e imagens favoráveis ao regime. Afastava-se a instituição escolar de um papel crítico. Os temas abordados no jornal escolar reforçavam, ideologicamente, a aparente objetividade de fatos mostrados através de uma história tradicional. A relação de aprendizagem entre alunos e professores, de que é exemplo, estava, pois, condicionada à reprodução.

O conteúdo do Tudo pelo Brasil era nutrido pelo mesmo esquema ideológico que reafirmava as razões do sistema político ser o que era: espelhava a imagem que o poder político fazia de si próprio. E foi a partir dela que muitos pensaram a realidade. Dessa forma, o estudo da ação ideológica nos serve como importante elemento para análise e compreensão dos fenômenos educacionais.

Entretanto, sua análise amplia as possibilidades de estudo das características da escola primária durante o Estado Novo. E mostra o quanto 
o projeto educacional estava submisso a um projeto político. Os exemplares do jornal escolar estudado servem como indicadores do 'clima' vivido pela instituição, num dado período. Nesse sentido, pretendia-se uma escola que assimilasse o viés político-ideológico do contexto. Sob certos aspectos, considerando as especificidades da realidade do Brasil nos anos 1930-40, é possível alguma identificação entre o Estado Novo conduzido por Getúlio Vargas e expressões do fascismo europeu.

Quanto à utilização do sistema escolar como estratégia formadora da infância e juventude, os diversos modos de uso de recursos de propaganda, discutidos neste estudo com base no teor de diferentes números de um jornal escolar de autoria de crianças da escola elementar, ratificam certo padrão de atuação embasado pelo fascismo. Uma versão configurada pelo regime do Estado Novo que, no Brasil, entre 1937 e 1945, guindou Getúlio Vargas a condição de grande Chefe da Nação!

Desta forma, como no Catecismo Cívico do Brasil Novo, veículo de propaganda que desde o próprio nome confere a si mesmo uma missão religiosa e messiânica de formação moral, reavivavam-se constantemente os pressupostos fascistas do Estado Novo. Naquele Catecismo, o próprio Getúlio assina:

Restauremos a Nação na sua autoridade e liberdade de ação: - na sua autoridade, dando-lhe os instrumentos de poder real e efetivo com que possa sobrepôr-se às influências desagregadoras, internas ou externas; na sua liberdade, abrindo o plenário do julgamento nacional sôbre os meios e os fins do Govêrno e deixando-a construir livremente a sua história e o seu destino (Departamento Nacional de Propaganda, 1937).

Assim, no âmbito do Estado Novo brasileiro, a campanha elaborada sob a vigorosa condução de Getúlio Vargas chegou às escolas elementares no sul do Brasil e, como um remédio cuidadosamente administrado a uma criança doente, foi inoculando 'gota a gota' as idéias de um nacionalismo de cores fascistas.

\section{Notas}

1 Em língua italiana no original. A tradução é de nossa responsabilidade.

2 Olga Benário Prestes, mulher do líder comunista, foi entregue ao Reich nazista e morreu num campo de concentração. 
3 Segundo Kreutz (1994, p. 35): "Em 1900 havia no Rio Grande do Sul 308 escolas de língua alemã, sendo 153 católicas e 155 evangélicas". Somente no Estado do Rio Grande do Sul, em 1937 havia 513 escolas evangélicas em regiões de imigração alemã (cf. Müller, 1994, p. 69). Conforme Gertz (1987, p. 57), "De acordo com dados fornecidos pelo Handwörterbuch des Grenz - und Auslanddeutschtums havia no Rio Grande do Sul, em 1930, 36933 alunos matriculados em escolas privadas 'alemãs' e em Santa Catarina 10 593".

4 Destacamos os quatro decretos de maior impacto na realidade das escolas e em suas comunidades: o Decreto lei $n^{\circ} 383$, de 18 de abril de 1938, que proibia aos estrangeiros o exercício de atividades políticas no Brasil; o Decreto $n^{\circ} 406$, de 4 de maio 1938, que regulamentava o ingresso e a permanência de estrangeiros, ditando providências para sua assimilação e criando o Conselho de Imigração e Colonização como órgão executor de suas disposições; o Decreto $n^{\circ} 868$, de 18 de novembro de 1938, que instituiu a Comissão Nacional de Ensino Primário, que possuía entre suas atribuições a nacionalização do ensino nos núcleos estrangeiros; e o Decreto $n^{\circ} 948$, de 13 de dezembro do mesmo ano, que, considerando a complexidade das medidas para promover a assimilação dos colonos e completa nacionalização dos filhos de imigrantes, estabelecia que as medidas fossem tomadas pelo Conselho de Imigração e Colonização (cf. Bomeny, 1999, p. 158).

5 A influência da nacionalização em escolas primárias rurais - antigas escolas alemãs - desta mesma região tem sido objeto de nossas pesquisas e de outros autores que, igualmente, abordam os efeitos dos mecanismos de normatização e controle sobre aquelas instituições durante o Estado Novo. Sugerimos consultar as obras de Muller (1994), Kreutz (1999), Santos (2008) e Seyferth (2003).

6 Normalista era o título dado às professoras formadas na escola secundária - a Escola Normal - para atuar em escolas elementares.

7 O Duque de Caxias (1803-1880) é considerado o patrono do exército brasileiro.

8 Tiradentes (1746-1792) é evocado como o mártir da independência do Brasil, tendo sido enforcado e esquartejado como líder de uma insurreição contra o domínio português.

9 A independência do Brasil da colonização portuguesa é datada de 7 de setembro de 1822.

10 José Bonifácio (1763-1838) foi importante ator político no movimento da independência do Brasil.

11 O Marechal Deodoro da Fonseca (1827-1892) foi o primeiro Presidente da República.

12 Considerado o pai da aviação, Santos Dumont (1873-1932) é cultuado como exemplo de brasileiro.

13 Numa edição do jornal Correio do Povo, datada de 17 de outubro de 2000, na seção chamada "História, Fatos e Tradição", consta uma matéria sobre a inauguração da Prefeitura e do Fórum de Jaraguá do Sul, ilustrada por duas fotos, sendo uma delas da construção do prédio e a outra uma visão geral da praça em que se distinguem aqueles vários personagens presentes naquele dia 3 de outubro de 1941, sendo perfeitamente visíveis os estudantes em formação, perfilados para a cerimônia. 
14 Para essa temática, ver o artigo de Martin Dreher (1994) "O Estado Novo e a Igreja Evangélica Luterana".

15 A obra do autor Olavo Bilac foi eleita pelos defensores do nacionalismo como referência para utilização nas escolas brasileiras nas primeiras décadas do século $\mathrm{XX}$. Por isso, seus textos e poemas, particularmente os que apresentam uma infância sob perspectiva militarista, recorrendo a questões como a obediência e devoção a Pátria, atendiam perfeitamente aos princípios do nacionalismo da era Vargas.

\section{Referências}

Almeida, M. G. A. A. (1998). Estado Novo: Projeto político pedagógico e a construção do saber. Revista Brasileira de História, 18(36), 137-159.

Amaral Peixoto, A. V. (1960). Getúlio Vargas, meu pai (2a ed.). Porto Alegre: Editora Globo.

Bercito, S. D. R. (1990). Nos tempos de Getúlio: Da revolução de 30 ao fim do Estado Novo. São Paulo: Atual.

Bethlem, H. (1939). Vale do Itajaí - Jornadas de civismo. Rio de Janeiro: Livraria José Olympio Editora.

Bomeny, H. M. B. (1999). Três decretos e um ministério: A propósito da educação no Estado Novo. In D. Pandolfi (Org.), Repensando o Estado Novo (pp. 137-166). Rio de Janeiro: Ed. Fundação Getúlio Vargas.

Comemorações do Estado Nacional - 1937 - 1942 - Na voz das classes e na palavra do chefe (1943). Rio de Janeiro. [S.I.].

Departamento Nacional de Propaganda (1937). Catecismo Cívico do Brasil Novo. [S.I.: s.n.].

Departamento Nacional de Propaganda (1938). O Brasil é Bom. [S.I.: s.n.].

Dreher, M. (1994). O Estado Novo e a Igreja Evangélica Luterana. In T. L. Muller (Org.), Nacionalização e imigração alemã (pp. 87-110). São Leopoldo: Ed. Unisinos.

Escola Isolada Municipal Luiz Delfino (1941-1944). Tudo pelo Brasil [jornais escolares manuscritos, recolhidos no Arquivo Histórico de Jaraguá do Sul "Eugênio Victor Schmöckel"].

Faria, A. A., \& Barros, E. L. (1986). Getúlio Vargas e sua época (4ª ed.). São Paulo: Global Editora.

Gertz, R. (1987). O fascismo no sul do Brasil. Porto Alegre: Mercado Aberto.

Instituto Brasileiro de Estatística/Departamento Estadual de Estatística do Estado de Santa Catarina (1944). Ensino Primário Geral - 1944 - Informação anual àcêrca da organização e aproveitamento. Santa Catarina: Instituto Brasileiro de Estatística/Departamento Estadual de Estatística.

Kreutz, L. (1994). A escola teuto-brasileira católica e a nacionalização do ensino. In T. L. Müller (Org.), Nacionalização e imigração alemã (pp. 27-64). São Leopoldo: Ed. Unisinos. 
Kreutz, L. (1999). Identidade étnica e processo escolar. Cadernos de Pesquisa, São Paulo, 107, 79-96.

Müller, T. L. (Org.). (1994). Nacionalização e imigração alemã. São Leopoldo: Ed. Unisinos.

Oliveira, L. L., Velloso, M. P., \& Gomes, A. M. C. (1982). Estado Novo: Ideologia e poder. Rio de Janeiro: Zahar Editores.

Outhwaite, W., \& Bottomore, T. (Edit.). (1996). Dicionário do pensamento social do Século XX. Rio de Janeiro: Jorge Zahar Ed.

Pandolfi, D. (Org.). (1999). Repensando o Estado Novo. Rio de Janeiro: Ed. FGV.

Paulo, H. (1994). Estado Novo e propaganda em Portugal e no Brasil: o SPN, o SNI e o DIP. Coimbra: Livraria Minerva.

Santos, A. V. (2008). A inspeção escolar e a campanha nacionalista: Políticas e práticas na escola primária catarinense. Educação em Questão, 33(33), 229-252.

Scarzanella, E. (a cura di) (2005). Fascisti in Sud América. Firenze: Le Lettere.

Schwartzman, S., Bomeny, H. M. B., \& Costa, V. M. R. (1984). Tempos de Capanema. Rio de Janeiro: Paz e Terra; São Paulo: EDUSP.

Seyferth, G. (2003). A conflituosa história da formação da etnicidade teuto-brasileira. In N. A. Fiori (Org.), Etnia e educação: A escola "alemã" do Brasil e estudos congêneres (pp. 21-61). Florianópolis: Ed. da UFSC; Tubarão: Editora Unisul.

Trento, A. (2005). Dovunque è um italiano, là è il tricolore. La penetrazione del fascismo tra gli immigrati in Brasile. In E. Scarzanella (a cura di), Fascisti in Sud América (pp. 1-54). Firenze: Le Lettere.

Vargas, G. (1995). Diário. São Paulo: Siciliano; Rio de Janeiro: Fundação Getúlio Vargas. 


\section{EDUCATION AND FASCISM IN BRAZIL: THE SCHOOLING OF CHILDHOOD AND THE NEW STATE (1937-1945)}

Abstract

New State was the dictatorial government under Getúlio Vargas leadership. In this period the government action was characterized by reaching to build the Brazilian nationality and identity. This study evidences the ideological and political orientation of the New State that aims reach elementary schools, especially which situated in European immigration areas of Southern Brazil, generating pedagogical changes. We analyzed editions of a school newspaper called Everything for Brazil, elaborated between 1941 and 1944, and education policies documentation concerning management and school inspection. We showed that texts written by the children of the Brazilian elementary school and transported to the school newspaper explicit, through its form and contents, the ideas of the political regimen. As a curriculum activity, the childhood involvement in the newspaper construction would collaborate for citizenship that was Brazilian needs. In the New State, school education attends to nationalist construction idealized by the fascist project of Getúlio Vargas.

Keywords

Education; Nationalism; Fascism; Childhood; Brazil

\section{EDUCACIÓN Y EL FASCISMO EN EL BRASIL: ESCOLARIZACIÓN DE LA INFANCIA Y EL ESTADO NUEVO (1937-1945)}

\section{Résumé}

El Estado Nuevo fué el gobierno dictatorial encabezado por Getúlio Vargas. En este período la acción del gobierno se caracterizó por la búsqueda de la formación de la nacionalidad y de la identidad brasileña. En este estudio destacamos la orientación política e ideológica del Estado Nuevo que objetivó 
llegar a las escuelas primarias, especialmente a los sitios de la inmigración europea en el sur de Brasil, generando cambios pedagógicos. Analizamos ediciones de un periódico escolar llamado Todo por el Brasil, escritas entre 1941 y 1944, y los documentos de la legislación educativa como los informes de inspección de la escuela y actas. Demostramos que los textos escritos por niños de la escuela primaria y trasportados para el periódico escolar explicitán, en su forma y contenido, las ideas del régimen político. Como actividad del plan de estudios, la participación de los niños en la preparación del periódico podría colaborar en la formación de los ciudadanos que el Brasil necesitaba. En el Estado Nuevo, la educación servió al proyecto de construcción concebido por el fascismo nacionalista de Getúlio Vargas.

Palabras-clave

Educación; Nacionalismo; Fascismo; Infancia; Brasil

Recebido em Outubro/2009 Aceite para publicação em Maio/2012 